\title{
Evaluating eco-environment in urban agglomeration from a vegetation-impervious surface-soil-air framework: an example in Ningxia, China
}

\author{
Hao Sun $\odot,{ }^{\mathrm{a}, *}$ Ling $\mathrm{Wu},{ }^{\mathrm{a}, \mathrm{b}}$ Jiaqi Hu, ${ }^{\mathrm{a}}$ Liru Ma, ${ }^{\mathrm{a}}$ Huan $\mathrm{Li},{ }^{\mathrm{c}}$ and Dan $\mathrm{Wu}^{\mathrm{c}}$ \\ ${ }^{a}$ China University of Mining and Technology-Beijing, College of Geoscience and \\ Surveying Engineering, Beijing, China \\ ${ }^{\mathrm{b}}$ Satellite Application Center for Ecology and Environment, \\ Ministry of Ecology and Environment, China \\ ${ }^{c}$ Ningxia Institute of Remote Sensing, Survey and Mapping, Yinchuan, China
}

\begin{abstract}
Urban agglomerations (UA) are the fastest growing regional types during recent years, especially in developing countries. Monitoring and evaluating the eco-environment quality of UA is significant for sustainability. The previous remote sensing models of urban ecoenvironment are generally based on the vegetation-impervious surface-soil framework, which neglects the air quality in urban areas. We constructed a vegetation-impervious surface-soil-air (VISA) framework and derived a remote sensing model of UA eco-environment (RSUAE) based on the VISA. The RSUAE can integrate the greenness, dryness and imperviousness, moisture, heat, and air turbidity. The new model was evaluated by comparing with land cover types and the existing remote sensing-based ecological index and eco-environmental quality index models. Results demonstrated that RSUAE is valid to depict the difference of eco-environment quality among varied land cover types. The RSUAE model has general consistency with the existing models, while RSUAE takes into account well the air quality. The RSUAE was utilized to evaluate the eco-environment of UA along the Yellow River in Ningxia, China (NXUA) with MannKendall trend test. Results identified $78.69 \%$ of the area has no significant change trend, $18.73 \%$ of the area has a significant increasing trend, and $2.58 \%$ of the area suffers significant decreasing trend in eco-environment quality from 2001 to 2019. The Yanchi county has the best improvement in eco-environment quality, whereas sensitivity analysis indicates that it is more vulnerable than other counties. The analysis tool and method presented in this study provide a reference for other UAs. The evaluation results in NXUA are noteworthy for local management. (C) The Authors. Published by SPIE under a Creative Commons Attribution 4.0 Unported License. Distribution or reproduction of this work in whole or in part requires full attribution of the original publication, including its DOI. [DOI: 10.1117/1.JRS.15.014518]
\end{abstract}

Keywords: vegetation-impervious surface-soil framework; vegetation-impervious surface-soilair framework; urban agglomeration; eco-environment; remote sensing; Yellow River.

Paper 200754 received Oct. 23, 2020; accepted for publication Feb. 15, 2021; published online Mar. 11, 2021.

\section{Introduction}

City is the center of culture, capital, labor, and information. In 2018, 55\% of the world's population lived in urban areas, a proportion that is expected to increase to $68 \%$ by 2050 according to 2018 Revision of World Urbanization Prospects. ${ }^{1}$ With the socioeconomic development, cities tend to spatial cluster, which can be termed as urban agglomeration (UA). ${ }^{2}$ UA has become the fastest growing regional types in developing countries during the past several decades especially in China. ${ }^{3}$ Moreover, it usually accounts for a large proportion in local economic development. For instance, the UA along the Yellow River of Ningxia Hui Autonomous Region, China (NXUA) is known as the essence of Ningxia's economic and social development, since it only occupies $<40 \%$ of land area but produce more than $90 \%$ of gross domestic product and accommodate more than $90 \%$ of urban population in Ningxia. To achieve sustainable

*Address all correspondence to Hao Sun, sunhao@cumtb.edu.cn 
development of UA, it is necessary to develop an effective and efficient tool for monitoring the eco-environmental quality of UA. ${ }^{4}$

Many researchers have shown that integrating various indices presents more advantages than a single index in assessing the eco-environment quality. ${ }^{5-8}$ For example, Li et al. ${ }^{9}$ constructed an integrated eco-environmental vulnerability index for evaluating the upper reaches of Minjiang River-valley, China. Musse et al. ${ }^{10}$ proposed an urban environmental quality index to evaluate the eco-environment of the southern city of Cali, Colombia. Sun et al. ${ }^{11}$ using the pressure-state-response framework to assess the health levels of wetland ecosystem at the Hangzhou Bay, China. The Ministry of Ecology and Environment of China published its Technical Criterion for Ecosystem Status Evaluation (technical criterion, for short) in 2015, which established a comprehensive Eco-environmental Quality Indexes (EEQIs) for county area, province area, country area, ecological function area, city area, and nature reserve area. ${ }^{12}$ However, the above-mentioned models generally involve many indicators that are hard to be obtained, such as the noise average intensity, water qualification rate, pollutant emission intensity, and centralized sewage treatment rate. ${ }^{12}$ This imposes restrictions on long-term dynamic analysis and spatial continuous evaluation of eco-environment quality. Remote sensing technology can provide a variety of spatial and temporal data that are easily obtained for spatiotemporal evaluation of eco-environment quality. ${ }^{13}$ Therefore, efforts are made to develop the eco-environment evaluation model supported only by remote sensing data (hereafter remote sensing model).

In 2018, $\mathrm{Hu}$ and $\mathrm{Xu}^{14}$ proposed a remote sensing-based ecological index (RSEI) for assessing the eco-environment quality of urban areas. The RSEI integrated four remotely sensed indicators, i.e., normalized differential built-up and soil index (NDBSI), land surface temperature (LST), land surface moisture (LSM), and normalized differential vegetation index (NDVI). These remotely sensed indicators were considered as measurements of dryness (representing built area), heat (representing temperature), moisture (representing soil moisture), and greenness (representing vegetation) that are strongly correlated to ecological status. ${ }^{15}$ Conceptually, RSEI is expressed as a function of the four indicators: RSEI $=f$ (dryness, heat, moisture, and greenness). The RSEI has been applied to other cities or areas to reveal the comprehensive ecoenvironment quality. ${ }^{14-18}$ In 2020, a new remotely sensed urban surface ecological index (RSUSEI) was proposed by introducing the imperviousness in the above-mentioned RSEI. ${ }^{19}$ The RSUSEI was expressed conceptually as RSUSEI $=f$ (dryness, heat, moisture, greenness, and imperviousness), where imperviousness was measured by impervious surface cover (ISC) ${ }^{19}$ It is worth noting that both the RSEI and the RSUSEI are based on the classical vegetation-impervious surface-soil (V-I-S) framework. ${ }^{20}$ In this framework, urban surfaces were assumed to consist of three fractions of impervious, vegetation, and soil covers. Therefore, biophysical characteristics of impervious surface, vegetation, and soil were integrated in the comprehensive model. The dryness in the RSEI was measured by NDBSI, which integrates the information on impervious and soil covers. In contrast, the dryness in the RSUSEI was measured by Normalized Difference Soil Index that only correlated to the information of soil cover. In addition, the information of impervious cover was separately measured by ISC in the RSUSEI model. ${ }^{19}$ Thus, RSUSEI and RSEI belong to the same outcome of the V-I-S framework.

However, the V-I-S framework neglects the air pollution in urban areas. It should be noted that the air quality is one of the most important factors that are strongly correlated to urban ecological status. It can be directly perceived by urban resident. Moreover, the air quality especially the particulate matter (PM) has very adverse health effects on the human respiratory and cardiovascular system including asthma, emphysema, and lung cancer. ${ }^{21}$ Therefore, it is very necessary to integrate air quality in evaluating eco-environment of urban areas. In this study, we constructed a vegetation-impervious surface-soil-air (VISA) framework to monitor and evaluate the eco-environment of urban areas. All biophysical characteristics in VISA were measured by remotely sensed parameters. Furthermore, they were integrated into a comprehensive index by combining the weights determined by the principal component analysis (PCA) method. ${ }^{22}$ Subsequently, the VISA framework was implemented and applied for exploring the spatiotemporal variation of eco-environment quality in NXUA using Mann-Kendall trend test. Specific methods, materials, and results are presented in the next sections. 


\section{Methods}

\subsection{VISA Framework}

The VISA framework was an improvement of the classical V-I-S framework and their conceptual structures are shown in Fig. 1. In V-I-S framework, land cover in urban environments is a linear combination of three components: impervious, vegetation, and soil surfaces. Therefore, to model accurately the eco-environment of urban areas, the biophysical characteristics related to the impervious, vegetation, and soil surfaces were integrated. In contrast, four components are considered in the suggested VISA framework: impervious surface, vegetation, soil, and air pollution. As shown in Fig. 1, the V-I-S is conceptually described as a triangle while the VISA framework is expressed as a triangular pyramid. Therefore, in addition to the impervious, vegetation, and soil components, the measurement of air pollution is also considered. The VISA framework can be expressed as

$$
\text { VISA }=f(\text { Greenness, Dryness - Imperviousness, Moisture, Heat, Turbidity })
$$

where greenness, dryness-imperviousness, moisture, and heat represent biophysical characteristics of vegetation, impervious surface, and soil like the classical V-I-S framework. Turbidity is a representative biophysical characteristic of air in VISA framework.

In this study, greenness was measured by enhanced vegetation index (EVI), because of its ability in weakening the influence of aerosol and soil background, reducing the effect of vegetation saturation, and monitoring the growth and decline of sparse vegetation and dense vegetation sensitively. Referring to the classical RSEI model, the Dryness-Imperviousness was measured by the NDBSI. ${ }^{23}$ Moisture was measure by Wetness Index (WET) transformed from tasseled cap, ${ }^{24}$ and Heat was measured by LST. ${ }^{25,26}$ Aerosol optical depth (AOD) is defined as the integral of the extinction coefficient of the medium in the vertical direction. It can be used to characterize the atmospheric turbidity, and effectively reflect the regional air pollution degree. $^{27-30}$ Therefore, AOD is introduced to evaluate the air quality. Based on the VISA framework and the above remotely sensed indicators, we constructed a comprehensive evaluation index named remote sensing model of UA eco-environment (RSUAE), which can be expressed as the following equation:

$$
\text { RSUAE }=f(\text { EVI, NDBSI, WET, LST, AOD }) .
$$

Among the specific evaluation indicators, WET and EVI are positive indicators which means the greater the indicator value, the better the eco-environment quality. The other indicators, NDBSI, LST, and AOD are negative indicators which means the greater the indicator value, the worse the eco-environment quality. The following equation is used to standardize the positive or negative indicators:

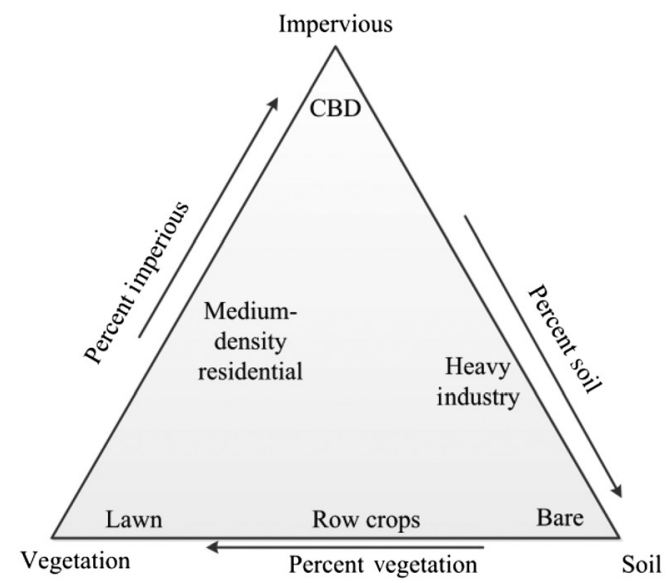

(a)

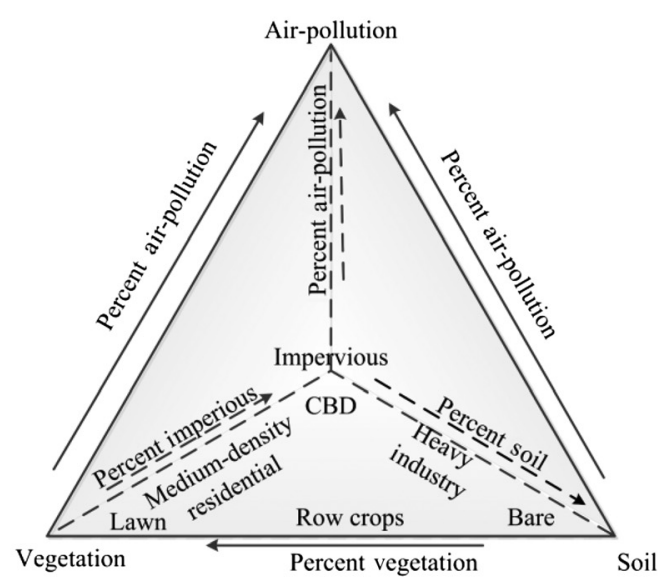

(b)

Fig. 1 Comparison of (a) classical V-I-S framework and (b) the suggested VISA framework. 


$$
\begin{cases}Z_{i}=\left(x_{i}-\mu\right) / \sigma, & \text { if positive indicator } \\ Z_{i}=\left(\mu-x_{i}\right) / \sigma, & \text { if negative indicator } \\ I_{i}=\left(e^{Z_{i}}-e^{-Z_{i}}\right) /\left(e^{Z_{i}}+e^{-Z_{i}}\right) & \end{cases}
$$

where $x_{i}$ is positive or negative remote sensing evaluation indicator; $\mu$ and $\sigma$ are the mean and standard values of the remote sensing index based on the statistics over the whole study area and during the whole study period; $Z_{i}$ is the $Z$-score standardized result of the $i$ 'th index; $I_{i}$ is the final hyperbolic-tangent normalization result which has a fixed range of $[-1,+1]$. Based on the normalized evaluation indicators, the RSUAE was finally calculated by the following equation:

$$
\operatorname{RSUAE}=\sum_{i=1}^{n} w_{i} \times I_{i}
$$

where $w_{i}$ is the weight of $I_{i} ; n$ is the number of evaluation indicators. Greater value of the RSUAE indicates better quality of the eco-environment, and vice versa. In this study, the $w_{i}$ was determined by the PCA transformation method:

$$
\left\{\begin{array}{l}
w_{i}=H_{i} / \sum_{i=1}^{n} H_{i} \\
H_{i}=\sum_{j=1}^{m}\left(\lambda_{i, j}\right)^{2}
\end{array}\right.
$$

where $H_{i}$ is communality of the $i$ 'th evaluation indicator; $\lambda_{i, j}$ is the loading or correlation between the $i$ 'th evaluation indicator and the $j$ 'th principal component; $m$ is the number of the top several components whose cumulative contribution ratio is $>95 \%$.

\subsection{Model Evaluation and Application}

To evaluate the RSUAE, we first evaluated the results with the land cover types, since many studies have shown that the quality of eco-environment is closely related to the types of land cover. ${ }^{31,32}$ The land cover types data were obtained from moderate-resolution imaging spectrometer (MODIS) Terra + Aqua combined land cover product (MCD12Q1). Moreover, we compared the RSUAE with the classical RSEI derived from the V-I-S framework. The RSEI consisted of four indicators: spectral vegetation index (EVI in here), WET, LST, and NDBSI.

$$
\mathrm{RSEI}=f(\mathrm{EVI}, \mathrm{NDBSI}, \mathrm{WET}, \mathrm{LST}) .
$$

Additionally, there is an EEQI, which integrated more indicators than that in RSEI. ${ }^{13}$ The EEQI employed the indicators of spectral vegetation index (EVI in here), WET, Albedo, index-based built-up index (IBI), salinization index (SI), and LST. Therefore, the EEQI was also employed in the evaluation of the RSUAE.

$$
\mathrm{EEQI}=f(\mathrm{EVI}, \mathrm{IBI}, \mathrm{WET}, \mathrm{LST}, \text { Albedo, SI }) .
$$

All the remote sensing indicators in the RSEI and EEQI were normalized with the same method as that in RSUAE and the weight determination methods were also uniform.

As an application case, the RSUAE was employed to explore the spatiotemporal change trend of eco-environment quality in NXUA, China. Mann-Kendall trend test is utilized for our spatiotemporal analysis, because (1) this method is a nonparametric test, which means it can work for all distribution; (2) it is a rank-based method that data outliers would not affect the results; and (3) this method has been widely used in analyzing the spatiotemporal variation of precipitation, temperature, and other land surface parameters. ${ }^{33-36}$ The chief output of the MannKendall trend test is a normalized test statistic $Z$ as follows:

$$
Z= \begin{cases}(S-1) / \sqrt{\operatorname{Var}(S)}, & \text { if } S>0 \\ 0, & \text { if } S=0 \\ (S+1) / \sqrt{\operatorname{Var}(S)}, & \text { if } S<0\end{cases}
$$


where the statistics $S$ and its variance $\operatorname{Var}(S)$ are calculated as

$$
\left\{\begin{array}{l}
S=\sum_{k=1}^{N-1} \sum_{j=k+1}^{N} \operatorname{sign}\left(R_{j}-R_{k}\right) \\
\operatorname{Var}(S)=\left[N(N-1)(2 N+5)-\sum_{p=1}^{g} t_{p}\left(t_{p}-1\right)\left(2 t_{p}+5\right)\right] / 18
\end{array}\right.
$$

where $N$ represents the number of data in the time series; $R_{j}$ and $R_{k}$ are the data at time $j$ and $k$, respectively; $\operatorname{sign}\left(R_{j}-R_{k}\right)$ is equal to 1 when $R_{j}>R_{k}$, to 0 when $R_{j}=R_{k}$, and to -1 when $R_{j}<R_{k} ; g$ is the number of tied groups where a tied group is a set of sample data having the same value; $t_{p}$ is the number of data points in the $p$ 'th group. For instance, the sequence $[8,6,8,6,3$, $6,5]$ has $N=7, g=2$, and $t_{1}=2$ for the tied value 8 , and $t_{2}=3$ for the tied value 6 . If $Z \leq-2.57$, the trend can be regarded as very significant decreasing. If $-2.57<Z \leq-1.96$, the trend can be said significant decreasing. When $-1.96<Z \leq 1.96$, there is no significant trend (NST). When $1.96<Z \leq 2.57$, we can say the trend is significant increasing. When $Z>2.57$, the trend is said to be very significantly increasing.

\section{Study Area and Data}

\subsection{Study Area}

The UA along the Yellow River in Ningxia includes Yinchuan, Shizuishan, Wuzhong, and Zhongwei cities. Figure 2 shows the location of the study area. There are nine land cover types identified by the MODIS MCD12Q1 products. They are evergreen needleleaf forests (ENF), open shrublands (OSH), savannas (SAV), grasslands (GRA), permanent wetlands (PWL), croplands (CRO), urban and built-up lands (URB), barren (BAR), and water bodies (WAT). This area belongs dry temperate continental climate, with annual sunshine hours of up to 2600 to $3000 \mathrm{~h}$, and the temperatures have large differences between day and night. ${ }^{37}$ Its average annual rainfall is about $200 \mathrm{~mm}$ and evaporation is far greater than rainfall (about 10 times of rainfall). ${ }^{38}$ As an essential area in Ningxia, monitoring its eco-environment is conducive to coordinate the relationship between local economic development and environment conservation.

\subsection{MODIS Data}

In this study, the VISA framework was performed with the support of MODIS products, including: Terra MODIS LST Products (MOD11A2); (2) MODIS Terra and Aqua combined Aerosol

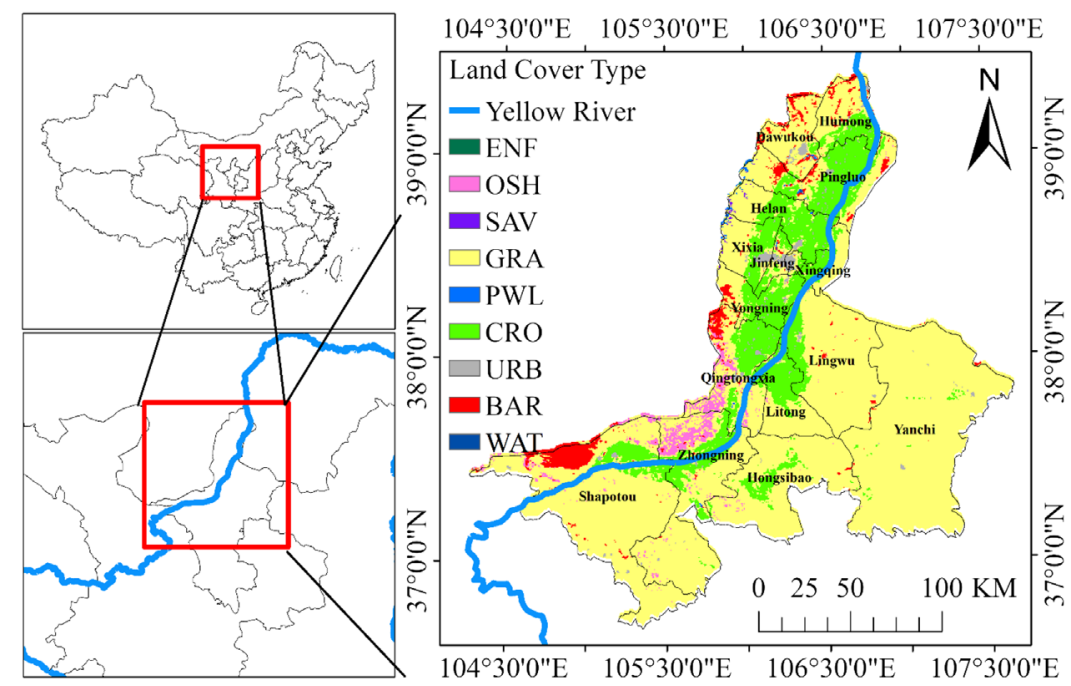

Fig. 2 Location of the study area in Ningxia, China, with the background of land cover type from MODIS product MCD12Q1 in 2017. 
Sun et al.: Evaluating eco-environment in urban agglomeration from a vegetation-impervious...

Table 1 MODIS Products Information used in this study.

\begin{tabular}{lccc}
\hline \hline Product name & Time resolution (day) & Space resolution $(\mathrm{km})$ & Period \\
\hline MOD11A2 & 8 & 1 & $2001-2019$ \\
MCD19A2 & 1 & 1 & $2001-2019$ \\
MOD13A2 & 16 & 1 & $2001-2019$ \\
MOD09A1 & 8 & 500 & $2001-2019$ \\
MCD43A3 & 1 & 500 & $2001-2019$ \\
\hline \hline
\end{tabular}

Products (MCD19A2); (3) Terra MODIS vegetation indices products (MOD13A3); and (4) MODIS surface reflectance products (MOD09A1). To implement the EEQI, MODIS Albedo products (MCD43A3) were also utilized. Table 1 gives specific information and time range of these products.

The LST, EVI, Albedo, and AOD were directly obtained from the corresponding MODIS products. There are blue band $(0.47 \mu \mathrm{m})$ and green band $(0.55 \mu \mathrm{m})$ AOD over land in MCD19A2. For convenience, they were averaged into one combined AOD. Additionally, there are black-sky albedo and white-sky albedo for shortwave broadband in MCD43A3. For the same reason of convenience, the black-sky albedo of shortwave broadband was selected. The IBI, NDBSI, SI, and WET ${ }^{24}$ are calculated by the MOD09A1 spectral reflectance using the following equations:

$$
\begin{aligned}
& \mathrm{SI}=\sqrt{\rho_{b 3} \times \rho_{\mathrm{b} 1}}, \\
& \mathrm{IBI}=\frac{\frac{2 \rho_{\mathrm{b} 6}}{\rho_{b 6}+\rho_{\mathrm{b} 2}}-\frac{\rho_{\mathrm{b} 2}}{\rho_{\mathrm{b} 2}+\rho_{\mathrm{b} 1}}-\frac{\rho_{\mathrm{b} 4}}{\rho_{\mathrm{b} 4}+\rho_{\mathrm{b} 6}}}{\frac{2 \rho_{\mathrm{b}}}{\rho_{\mathrm{b} 6}+\rho_{\mathrm{b} 2}}+\frac{\rho_{\mathrm{b} 2}}{\rho_{\mathrm{b} 2}+\rho_{\mathrm{b} 1}}+\frac{\rho_{\mathrm{b} 4}}{\rho_{\mathrm{b} 4}+\rho_{\mathrm{b} 6}}}, \\
& \mathrm{NDBSI}=\frac{1}{2}\left[\frac{\left(\rho_{b 6}+\rho_{\mathrm{b} 1}\right)-\left(\rho_{\mathrm{b} 2}+\rho_{b 3}\right)}{\left(\rho_{b 6}+\rho_{\mathrm{b} 1}\right)+\left(\rho_{\mathrm{b} 2}+\rho_{b 3}\right)}+\mathrm{IBI}\right], \\
& \mathrm{WET}=0.1147 \times \rho_{\mathrm{b} 1}+0.2489 \times \rho_{\mathrm{b} 2}+0.2408 \times \rho_{\mathrm{b} 3}+0.3132 \times \rho_{\mathrm{b} 4} \\
& -0.3122 \times \rho_{\mathrm{b} 5}-0.6416 \times \rho_{\mathrm{b} 6}-0.5087 \times \rho_{\mathrm{b} 7},
\end{aligned}
$$

where $\rho$ represents spectral reflectance, the subscripts $b 1$ to $b 7$ are spectral bands from 1 to 7 in MOD09A1. For the evaluation indexes derived from the products with a spatial resolution of $500 \mathrm{~m}$, they were aggregated into a spatial resolution of $1 \mathrm{~km}$ with averaging method. In time dimension, all the evaluation indexes were aggregated into a temporal resolution of one year with the way of taking median to avoid outliers.

\section{Results}

\subsection{Evaluation of the RSUAE Model with Land Cover Types}

Figure 3 revealed the spatial distribution of the RSUAE from 2002 to 2018 in every two years. It is noted that the RSUAE has a fixed variation range within $[-1,1]$. The RSUAE of -1 represents very bad eco-environment with low EVI, low WET, and high NDBSI, LST, and AOD. In contrast, the RSUAE of +1 represents very good eco-environment with high EVI, high WET and low NDBSI, LST, and AOD. The spatial distribution of RSUAE in Fig. 3 can be interpreted through combining with the land cover type information in Fig. 2. Agricultural land is mostly at a good level, while grassland is mostly at a moderate level. In 2006, the eco-environment quality of grassland decreased, but it gradually recovered over the next few years. Areas at poor 
Sun et al.: Evaluating eco-environment in urban agglomeration from a vegetation-impervious...

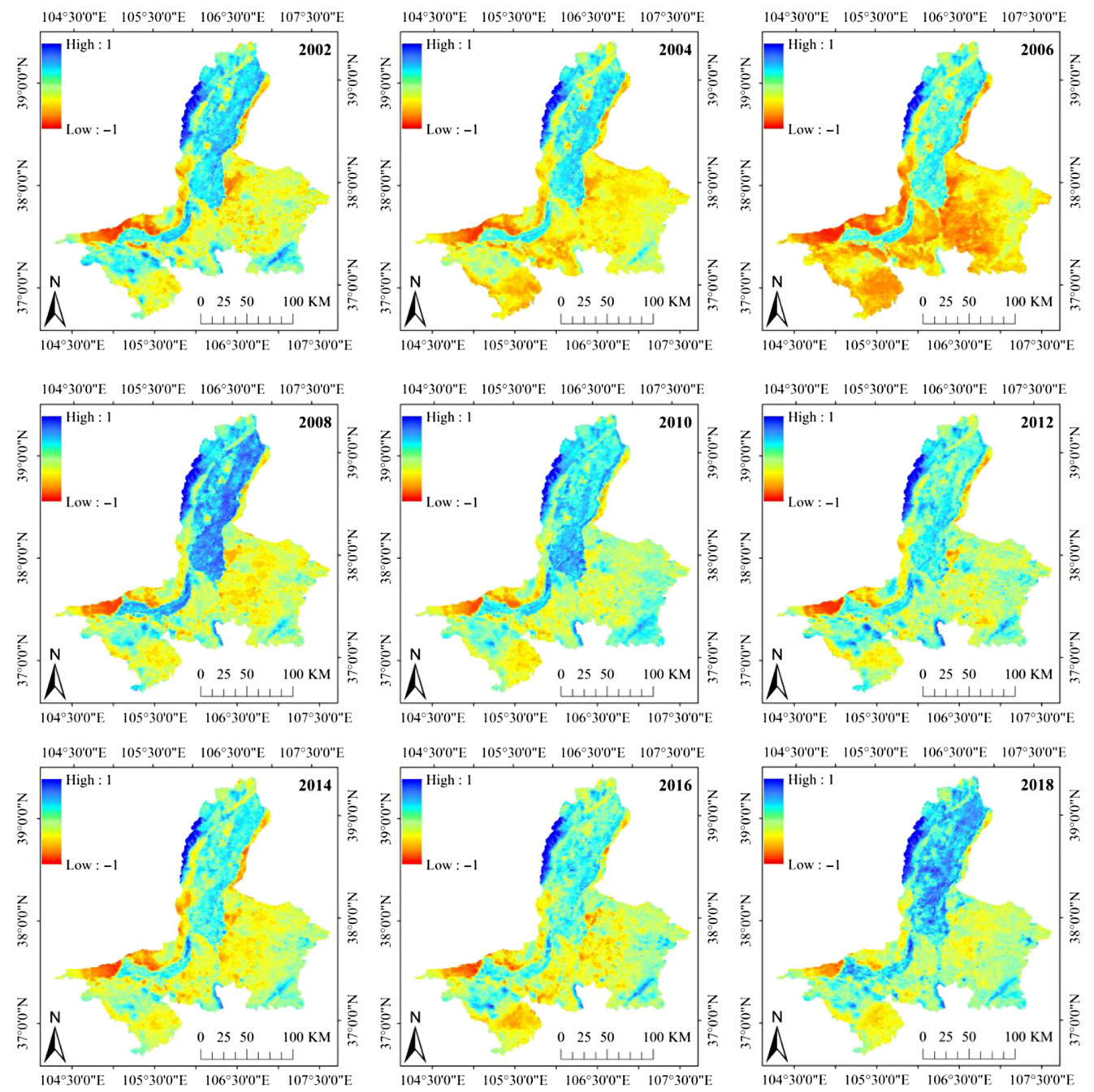

Fig. 3 Spatial distribution of RSUAE from 2002 to 2018 in every two years.

level are mostly distributed in bare land or sparse vegetation areas. Areas at very good levels are mostly distributed in forest areas.

Figure 4 quantitatively shows the mean RSUAE value of different land cover types over the study area. Results indicate that the RSUAE values of ENF, SAV, and PWL are normally high. They are at the first tier. The highest value may approach to 1 for ENF and SAV. The RSUAE values of CRO, WAT, and URB are normally at the second tier, which is also positive but lower than the value in the first tier. Due to the dry climate of this area, the grassland is very sparse. Therefore, the RSUAE values of grassland in the study area are around the value of zero. The BAR and OSH of the study area generally have negative values of RSUAE. Both the Figs. 3 and 4 demonstrated that the RSUAE values are consistent with the land cover types. In other words, the RSUAE model is valid from the comparisons with land cover type.

To evaluate the RSUAE in detail, Fig. 5 shows a comparison between the RSUAE value and the changes of land cover type in 2001 and 2017. Land cover type indicated that there was a large area of sparse grass land, i.e., Fig. 5(c) became agricultural land, i.e., Fig. 5(i) in Hongsibao county from 2001 to 2017. In consistent with this, the RSUAE results showed a trend of getting better in eco-environment quality, i.e., from Figs. 5(f) to 5(l). In Yanchi county, the RSUAE showed a trend of getting better from 2001 to 2017, i.e., from Figs. 5(e) to 5(k). Correspondingly, we can find that there are only sparse grass and bare land in Fig. 5(b), whereas we can find cropland in Fig. 5(h). Such detail in Fig. 5 provides another argument to validate the RSUAE model from the comparisons with land cover type. 


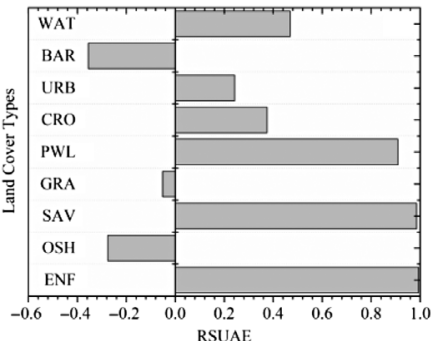

(a)

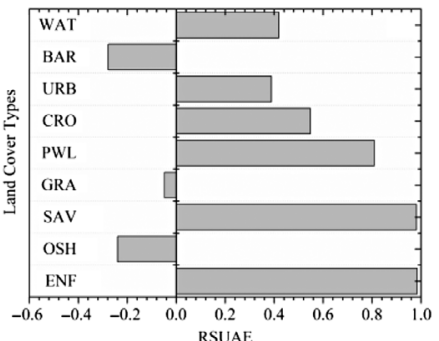

(d)

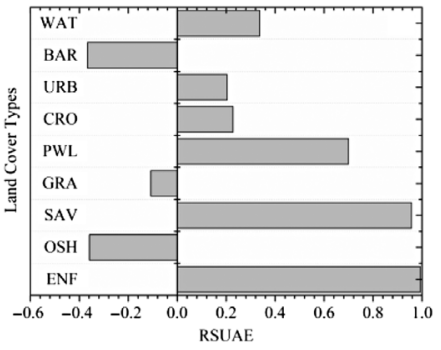

(g)

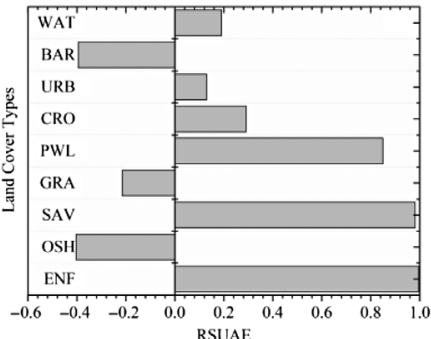

(b)

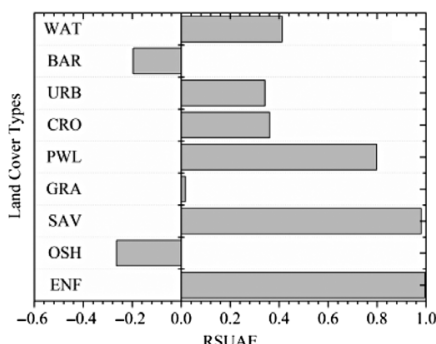

(e)

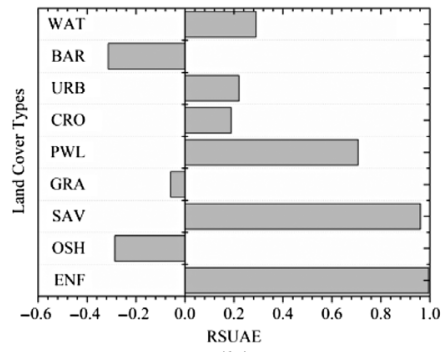

(h)

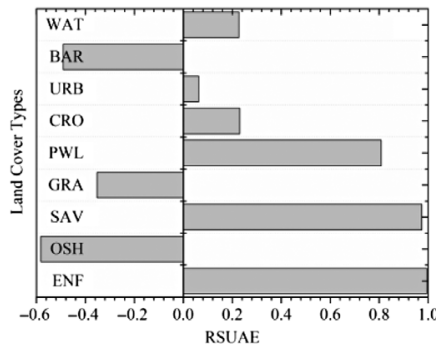

(c)

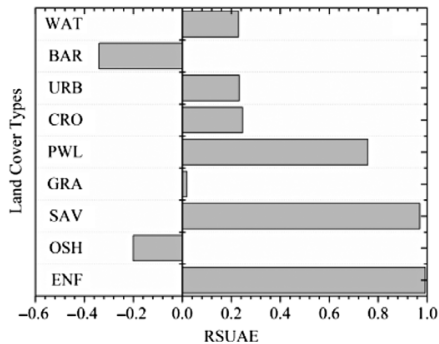

(f)

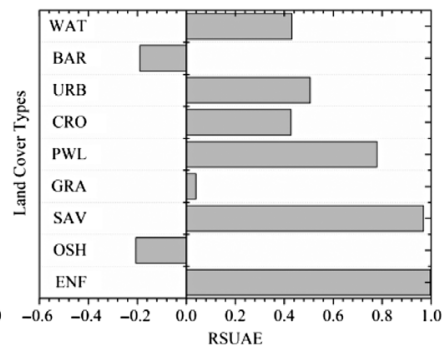

(i)

Fig. 4 Mean RSUAE of different land surface cover types in the study area where (a) to (i) correspond to different years from 2002 to 2018 with two-year step.

\subsection{Evaluation of the RSUAE Model with other Models}

To further validate the RSUAE model, Fig. 6 shows the correlation coefficients between the RSUAE against the EEQI and RSEI. The correlation coefficient between RSUAE and EEQI is expressed as $r$ (RSUAE \& EEQI). The correlation coefficient between RSUAE and RSEI is $r$ (RSUAE \& RSEI) and that between EEQI and RSEI is expressed as $r$ (EEQI \& RSEI). The Fig. 6(a) showed that the above-mentioned correlation coefficients are all $>0.85$ from 2001 to 2019. The results show that the RSUAE has well consistency with the EEQI and RSEI. However, there are also some differences among them as shown in Fig. 6(b), where $r$ (RSUAE \& AOD) is the correlation between RSUAE and AOD, $r$ (EEQI \&AOD) is the correlation between EEQI and AOD, and $r$ (RSEI \& AOD) is that between RSEI and AOD. As we know, AOD is a negative indicator to the eco-environment which means that the greater AOD indicates the worse eco-environment. Consequently, a reasonable eco-environmental indicator should present a relatively low or negative correlation with AOD. In Fig. 6(b), the $r$ (RSUAE \& AOD) is relatively low and sometimes negative, whereas the $r$ (EEQI \& AOD) and $r$ (RSEI \& AOD) are positive and relatively high. Consequently, the results in Fig. 6 show the validity of RSUAE from the comparison with the existing models.

Figure 7 shows a comparison among the AOD, RSEI, EEQI, and RSUAE over the north of the study area in 2013. The AOD shows significant high value over Jinfeng and Xixia districts and significant low value over the northwest area. The area with low AOD should get a relative high score while that with high AOD should get a relative low score in eco-environment evaluation. In Fig. 7, the northwest area has been recognized as high value area by the RSEI, EEQI, and RSUAE. However, the Jinfeng and Xixia districts did not been recognized as relative low 
Sun et al.: Evaluating eco-environment in urban agglomeration from a vegetation-impervious...

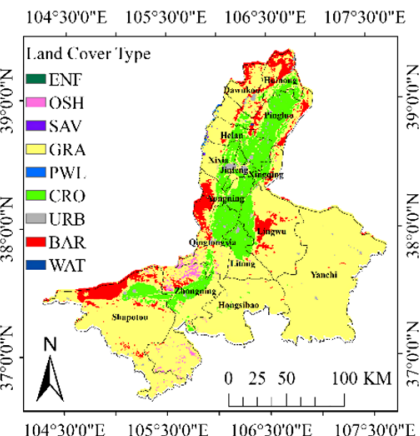

(a)

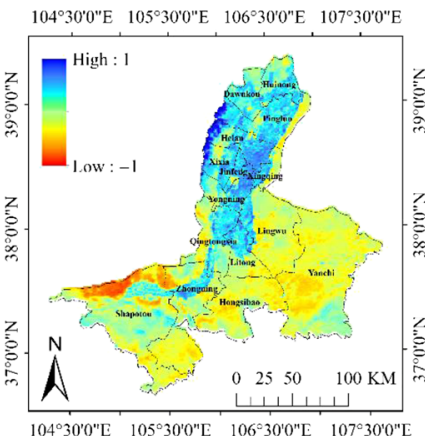

(d)

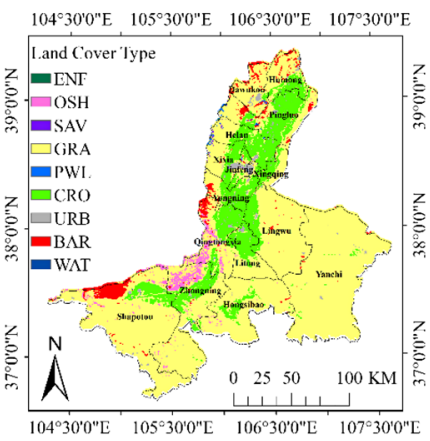

(g)

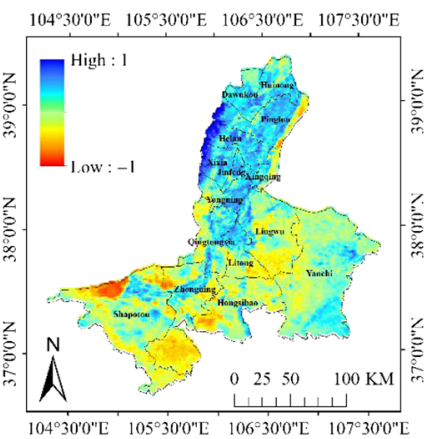

(j)

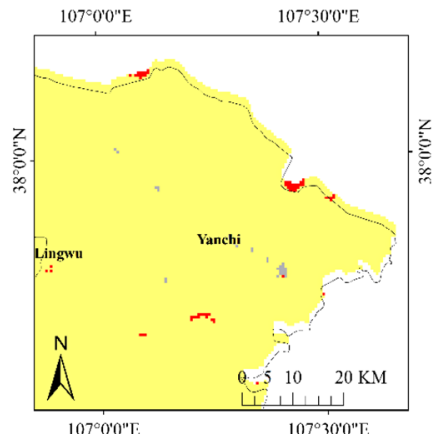

(b)

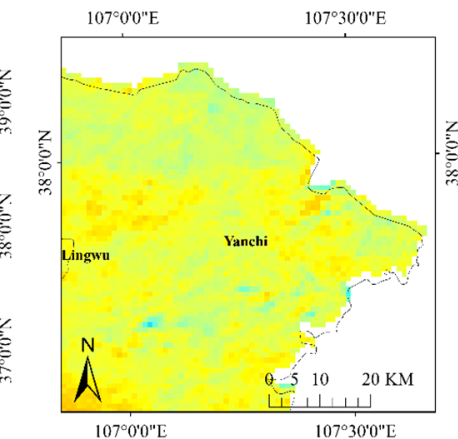

(e)

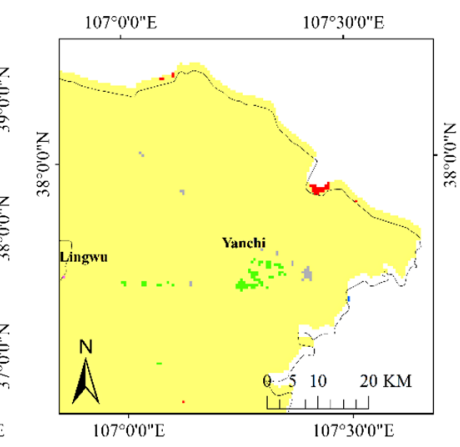

(h)

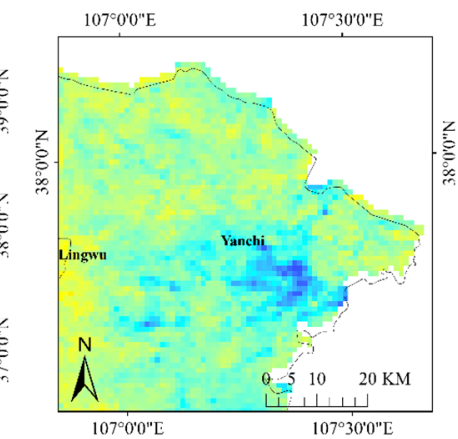

$(\mathrm{k})$

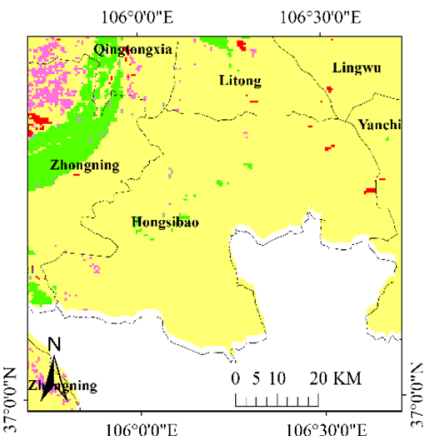

(c)

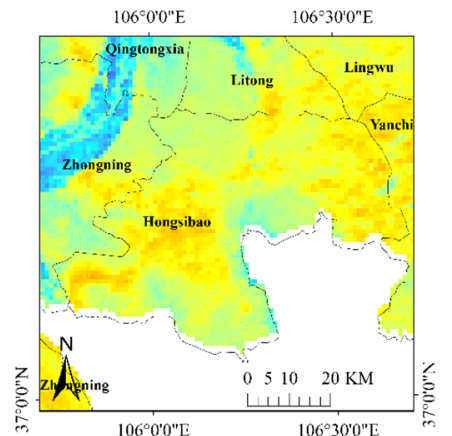

(f)

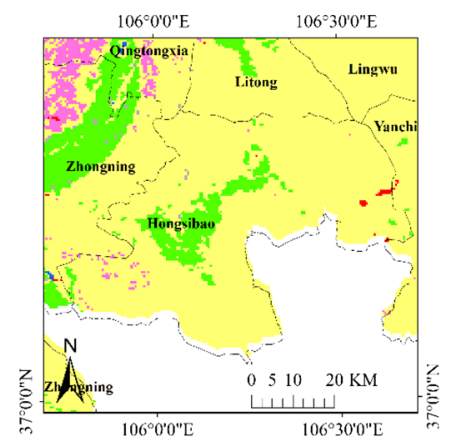

(i)

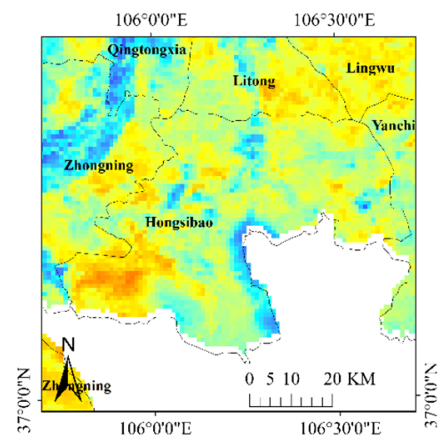

(1)

Fig. 5 A comparison between RSUAE and the land cover type in (a)-(f) 2001 and (g)-(l) 2017 where (a), (d), (g), and (j) are over the whole study area; (b), (e), (h), and (k) are over Yanchi county; (c), (f), (i), and (I) are over Hongsibao county.

value area by the RSEI and EEQI as shown in Figs. 7(b) and 7(c). In contrast, the two districts got a relative low value by the RSUAE as shown in Fig. 7(d). In short, Fig. 7 shows the validity of RSUAE from a comparison with the spatial distribution of AOD.

To sum up, we compared the RSUAE derived from the VISA framework with the RSEI and EEQI derived from the typical V-I-S framework from spatial and temporal perspectives in Figs. 6 
Sun et al.: Evaluating eco-environment in urban agglomeration from a vegetation-impervious...

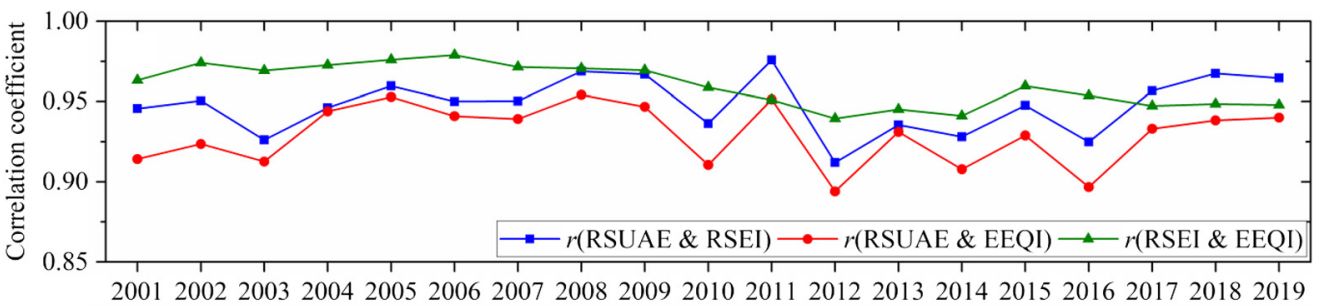

(a)

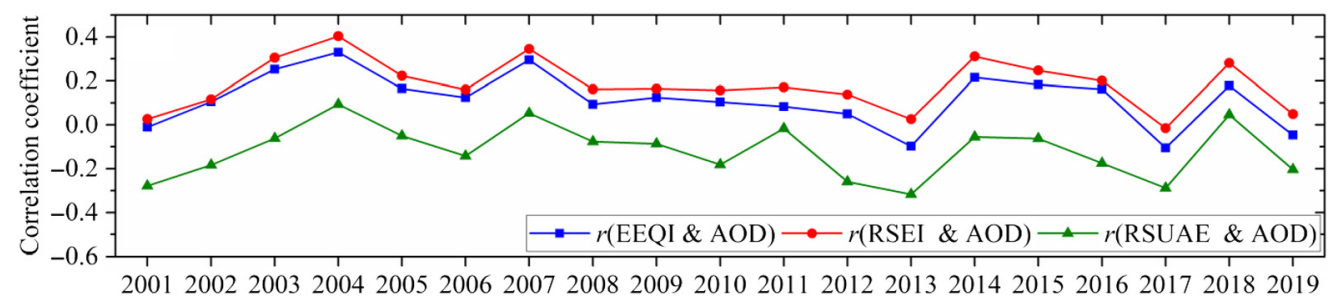

(b)

Fig. 6 (a) Correlation coefficients among RSUAE, EEQI, and RSEI. (b) Correlation coefficients between AOD and RSUAE, EEQI, and RSEI.

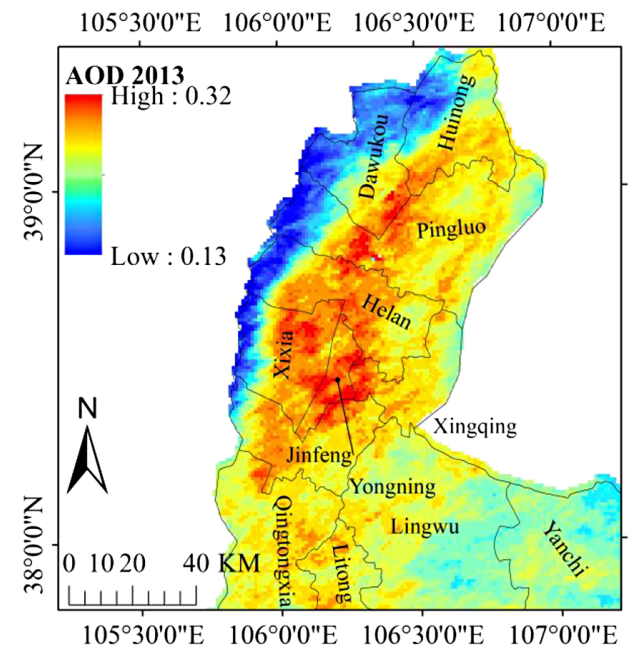

(a)

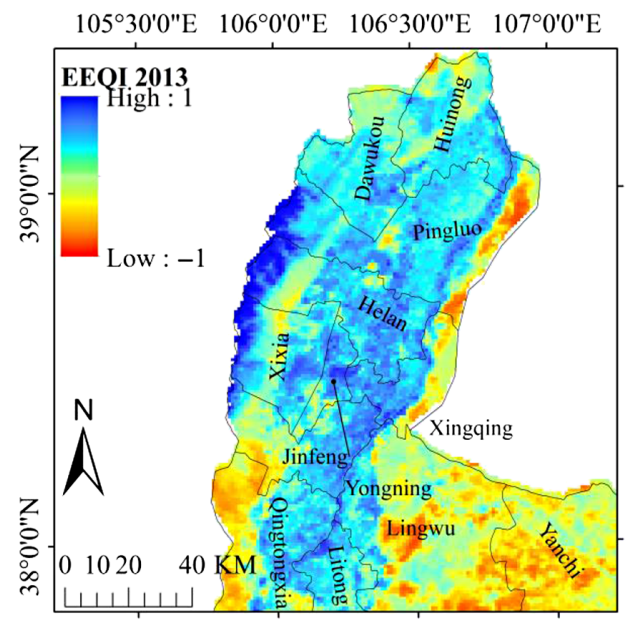

$105^{\circ} 30^{\prime} 0{ }^{\prime \prime} \mathrm{E} \quad 106^{\circ} 0^{\prime} 0^{\prime \prime} \mathrm{E} \quad 106^{\circ} 30^{\prime} 0 " \mathrm{E} \quad 107^{\circ} 0^{\prime} 0^{\prime \prime} \mathrm{E}$

(c)

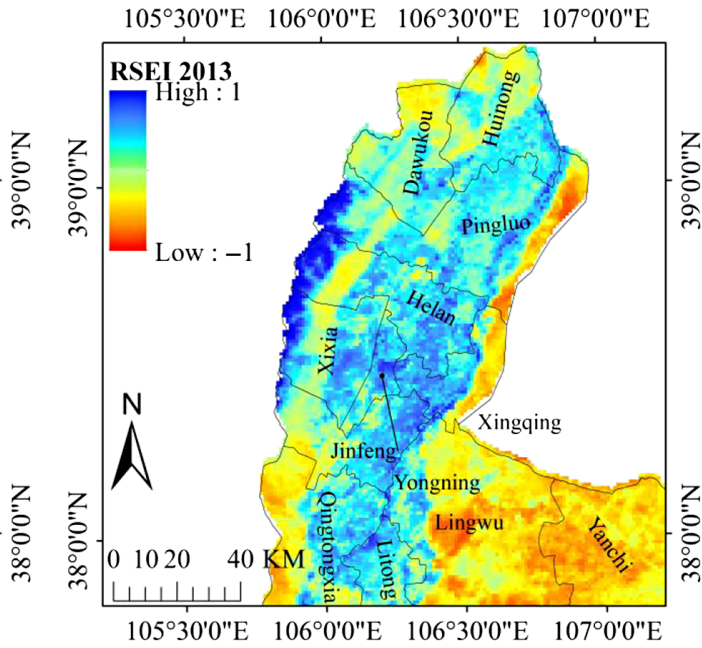

(b)

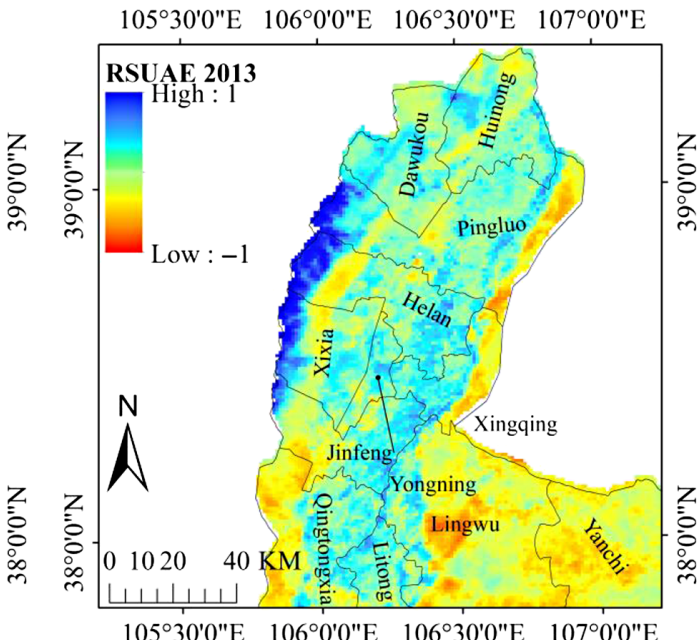

(d)

Fig. 7 A comparison among (a) AOD; (b) RSEI; (c) EEQl; and (d) RSUAE over the north of the study area in 2013. 
Sun et al.: Evaluating eco-environment in urban agglomeration from a vegetation-impervious...

and 7. The comparisons demonstrated that the RSUAE model maintained the advantages of existing models while taking into account the influences of air quality.

\subsection{Analyzing the Eco-Environment of NXUA Using RSUAE}

We first make a statistic for each RSUAE result over the whole study area. Results are shown in Fig. 8 where Fig. 8(a) shows the box plot for each RSUAE and Fig. 8(b) shows the average RSUAE from 2001 to 2019. The results shown that the average RSUAE over the whole area has an increasing trend implying that the whole eco-environment quality tends to get better. Most of all, we identified the years with very bad eco-environment. In 2005 and 2006, the average RSUAE values are very low indicating worse eco-environment than the other years. This result is consistent with actual situation reported by Ningxia Water Resource Bulletin that released by Ningxia Water Conservancy. ${ }^{39}$ It was reported that Ningxia suffered very serious drought from September 2004 to the end of 2006. The precipitation in 2005 reduced 31\% as compared with longtime average annual value. As a result, the longtime drought had caused widespread crop damage and made grassland cannot be green. ${ }^{39}$

Figure 9 shows the results of Mann-Kendall trend test where VSD is very significant decrease; SD represents significant decrease; NST is no significant trend; SI is significant increase; and VSI is very significant increase. It shows that from 2001 to 2019 , most of the study area has NST. This area accounts for $78.69 \%$ of the whole study area. Second, we can find some areas that have a significant increasing trend. Such kind of area holds about $18.73 \%$ of the whole area. The rest of the study area suffers significant or very significant decreasing trend, which occupies about $2.58 \%$ of the whole area. Figures 9(c) and 9(d) show the average and standard deviation of the $Z$ value for each district in the study area. The Yanchi county get the highest average $Z$ value and a low standard deviation demonstrating that the eco-environment quality in most areas of Yanchi has improved significantly. In contrast, the Xingqing and Dawukou counties have the lowest average $Z$ value and a high standard deviation, which means that the eco-environment change is very uneven and the average condition shows no significant change. The other counties should learn experience from Yanchi and lessons from Xingqing and Dawukou counties.

We imported the Mann-Kendall trend test result into Google Earth to analyze the areas where eco-environment quality suffers degradation. Results are shown in Fig. 10, which presents four distinct areas where significant or very significant decline of RSUAE were found. The first is at the northwest of the Shizuishan city. The second one is around Yinchuan city. The third area is around Wuzhong city, and the fourth one is around Zhongning city. The eco-environment's degradation around city such as the Yinchuan, Wuzhong, and Zhongning may come from the city's

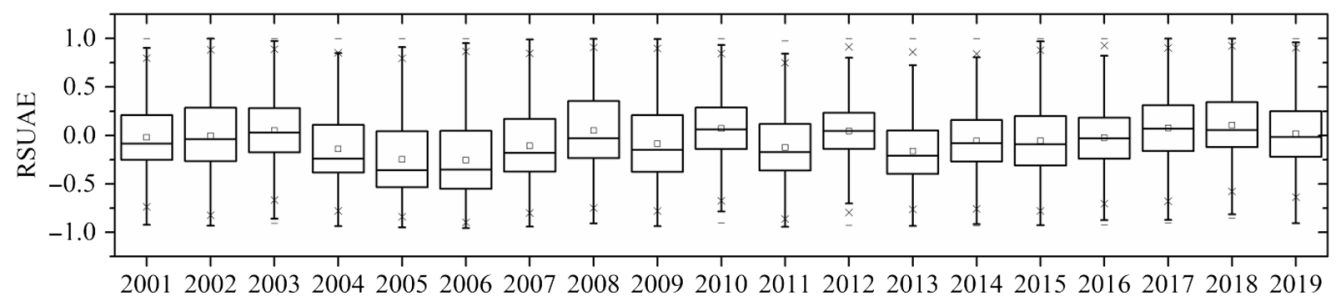

(a)

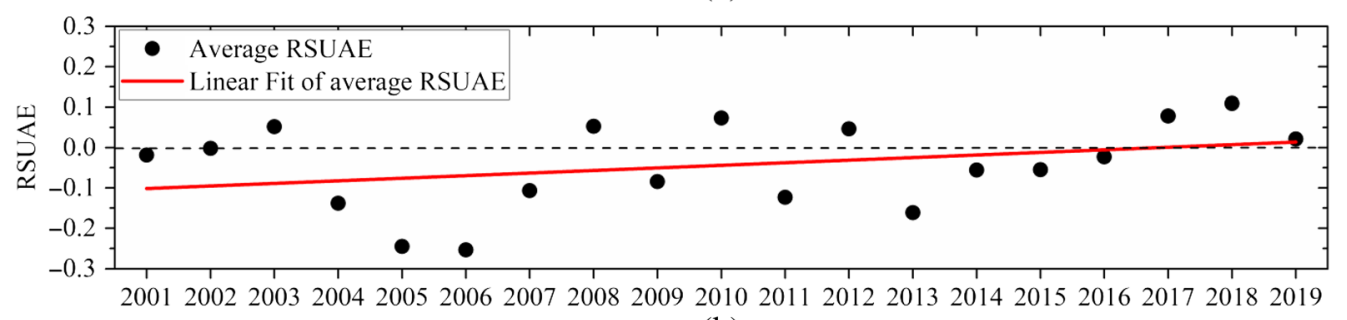

(b)

Fig. 8 Statistics of RSUAE from 2001 to 2018 over the whole area where (a) is the box plot and (b) is the average RSUAE. 


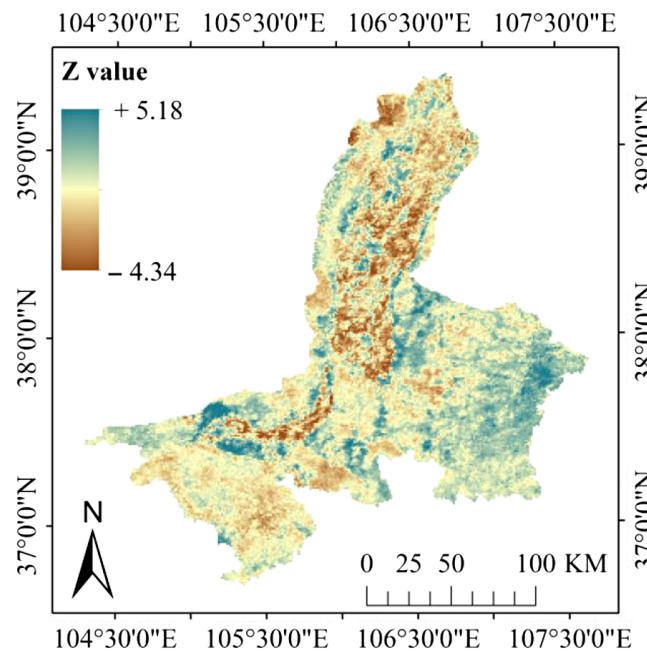

(a)

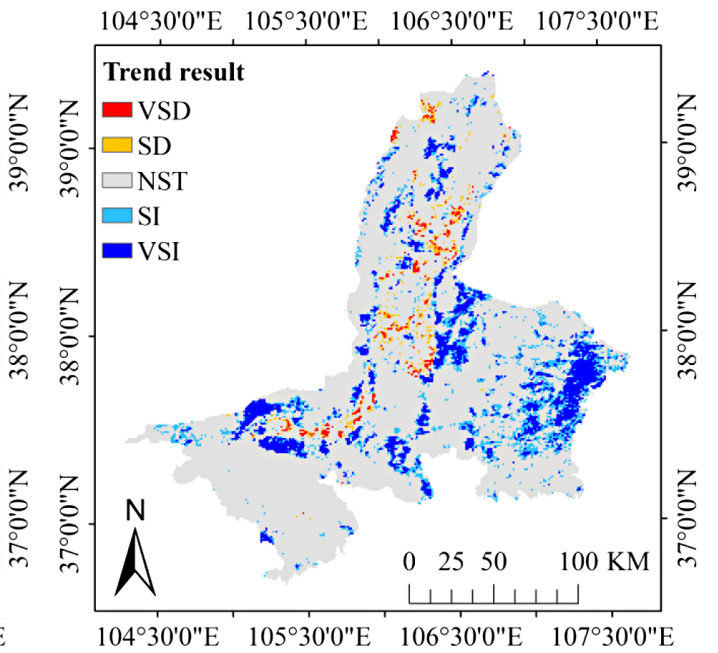

(b)

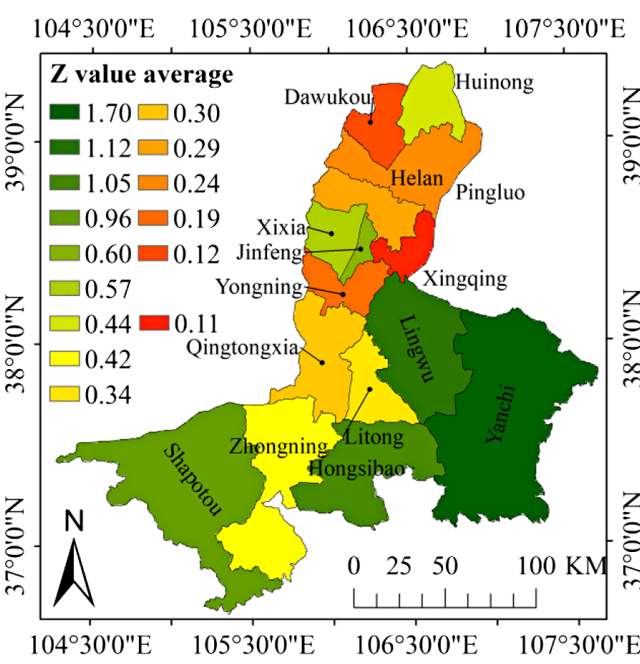

(c)

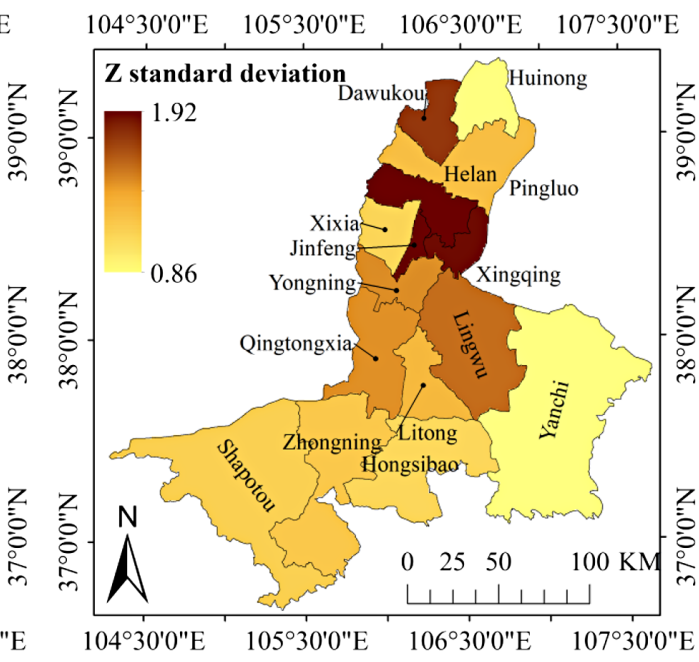

(d)

Fig. 9 Mann-Kendall trend test results of RSUAE from 2001 to 2018 where (a) is the $Z$ value; (b) is grade of $Z$ value; (c) is the average $Z$ value; an (d) is the standard deviation of $Z$ value.

expansion..$^{40}$ The degradation areas around these cities need to be paid further attention for sustainability. More importantly, the northwest area of the Shizuishan city need to be taken seriously, because this area is located in the Heland mountain and this mountain is an important geographical boundary playing an important role in water source conservation in northwest China.

\section{Discussion}

\subsection{Sensitivity Analysis}

Analyzing the sensitivity of the RSUAE model to individual evaluation indicator is beneficial to further understand this model. Taking the data in 2018 as an example, we made a perturbation of increasing $20 \%$ or decreasing $20 \%$ in one remote sensing indicator while keeping the other indicators unchanged. For LST, the perturbation is increasing $2 \mathrm{~K}$ or decreasing $2 \mathrm{~K}$. Subsequently, the relative change of RSUAE can be calculated by (RSUAE' - RSUAE)/ $\mid$ RSUAE $\mid$ where RSUAE is original value and the RSUAE' is the varied value corresponding to the perturbations in remote sensing indicators. The greater relative change value indicates the higher sensitivity of RSUAE to that indicator and vice versa. 


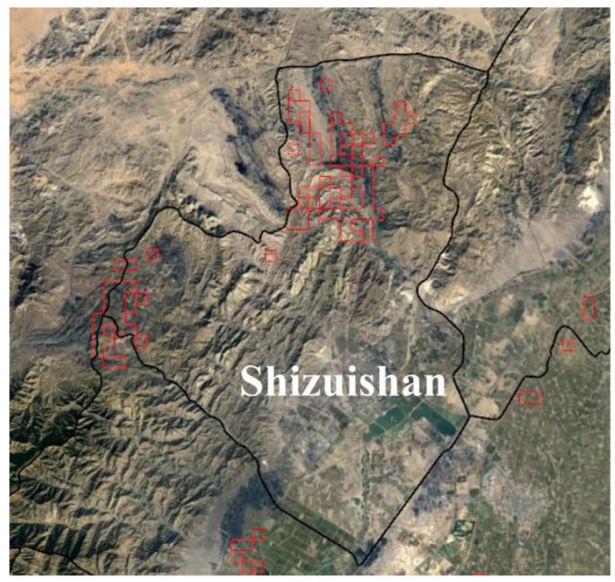

(a)

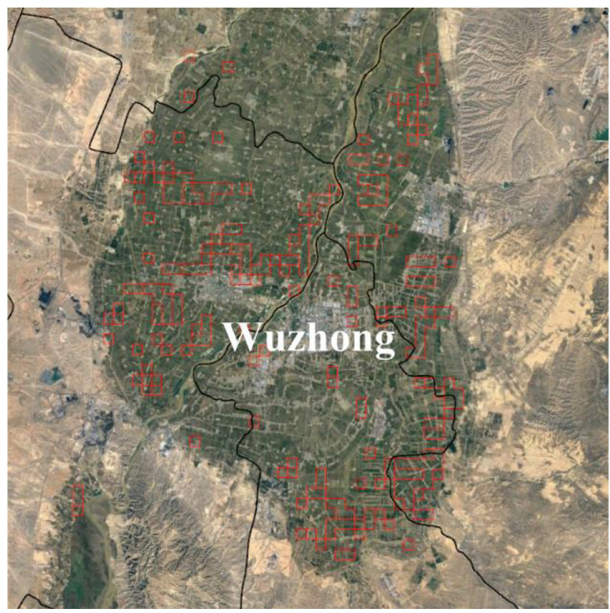

(c)

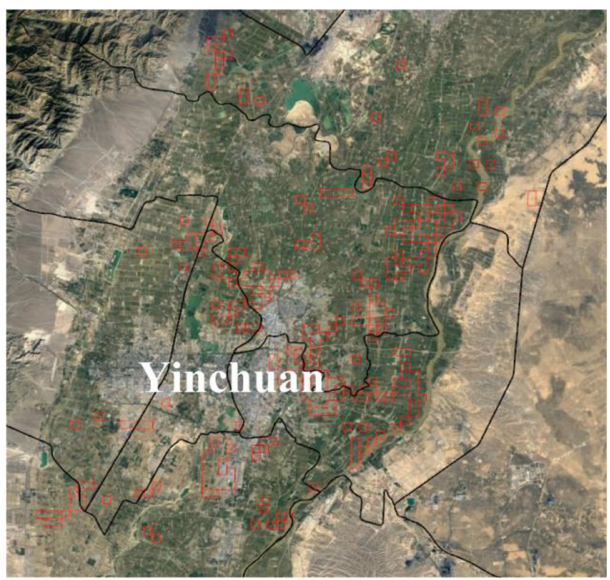

(b)

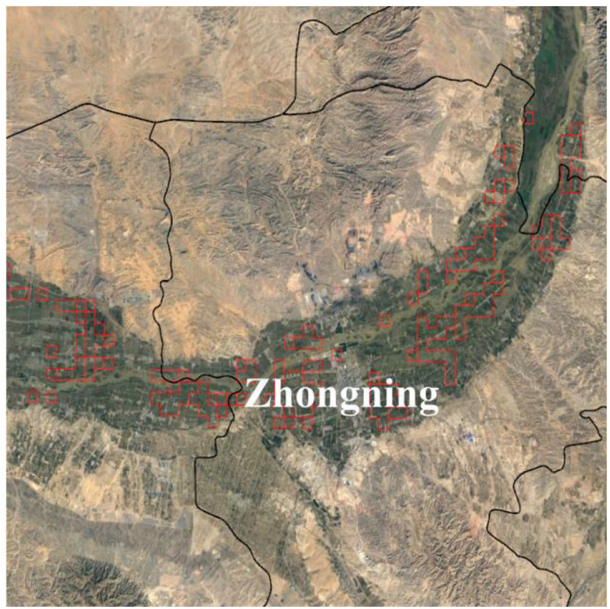

(d)

Fig. 10 Several areas where eco-environment quality suffers degradation. (a) Northwest of Shizuishan city. (b) Around Yinchuan city. (c) Around Wuzhong city. (d) Around Zhongning city. The background images are from Google Earth.

Figures 11 and 12 show the sensitivity results through increasing and decreasing the five indicators, respectively. The relative change was divided into the same 12 levels. Results show that RSUAE is positively correlated with EVI and WET while it is negatively correlated with AOD, LST, and NDBSI. When EVI or WET decrease by $20 \%$, the RSUAE would suffer significant decrease especially in the southeast area. When NDBSI and AOD increase by $20 \%$ or the LST increase $2 \mathrm{~K}$, the RSUAE would also suffer significant decrease and the southeast area is also the more sensitive area. Therefore, we can conclude that the southeast area is more vulnerable to the change of eco-environment. Most of this vulnerable area locate in the Yanchi County which is a typical transitional zone of topography, climate, vegetation, as well as farming and animal husbandry modes of production. ${ }^{41}$ The local government should increase efforts to protect the ecological environment of this region.

\subsection{Contributions of this Study}

First, a VISA framework for evaluating the eco-environment of urban and UA area was constructed in this study. As we have mentioned, the classical RSEI model proposed in 2018, the RSUSEI proposed in 2020, and the EEQI proposed in 2019 are both based on the V-I-S framework. Within this framework, urban eco-environment was considered as a composition of vegetation, soil, and imperious surface. It neglects the air pollution which is a very important factor to the wellbeing of urban residents. Thus, we constructed the VISA framework 
Sun et al.: Evaluating eco-environment in urban agglomeration from a vegetation-impervious...

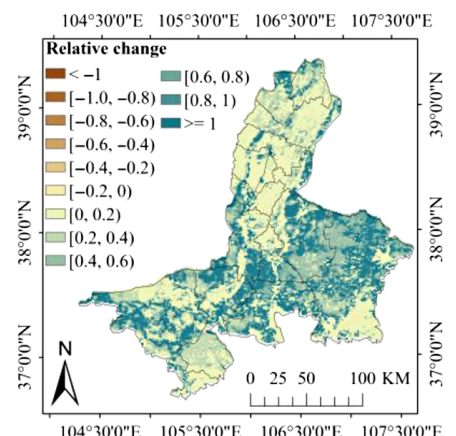

(a)

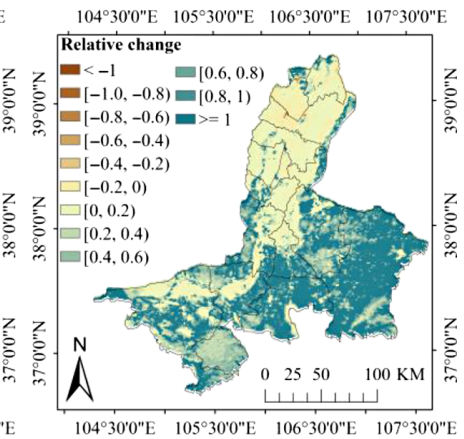

(b)

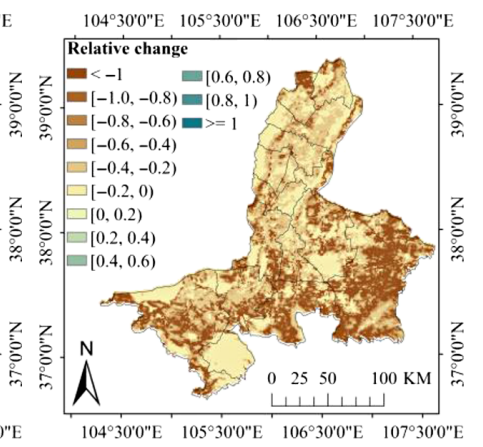

(c)

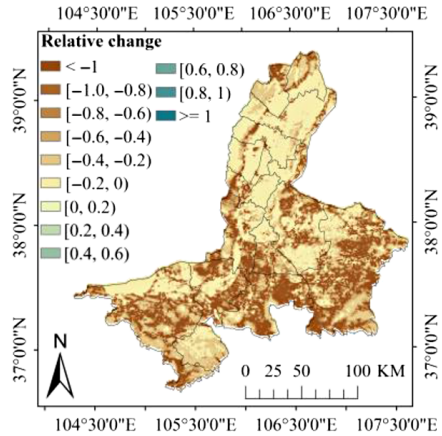

(d)

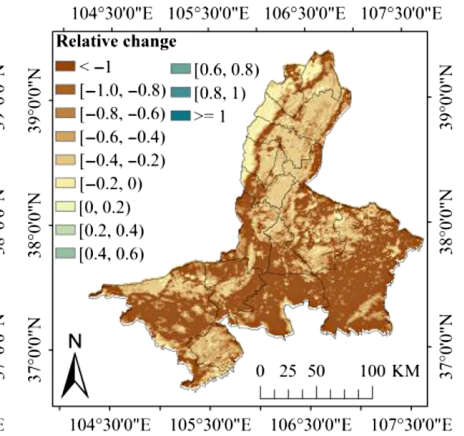

(e)

Fig. 11 Relative change of RSUAE to the perturbation of (a) EVI; (b) WET; (c) LST; (d) NDBSI; and (e) AOD through increasing LST by $2 \mathrm{~K}$ or increasing the other indicators by $20 \%$.

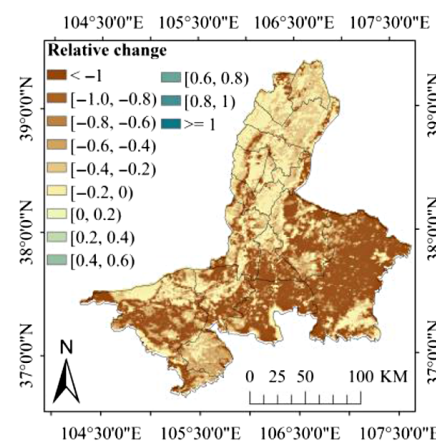

(a)

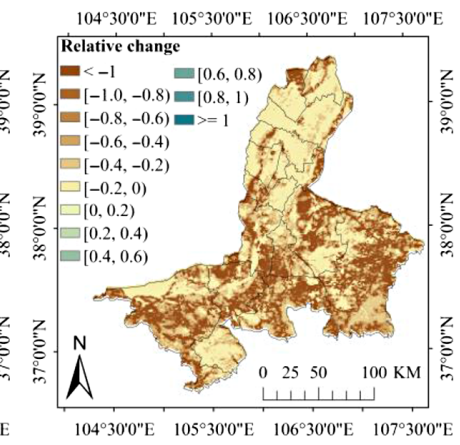

(b)

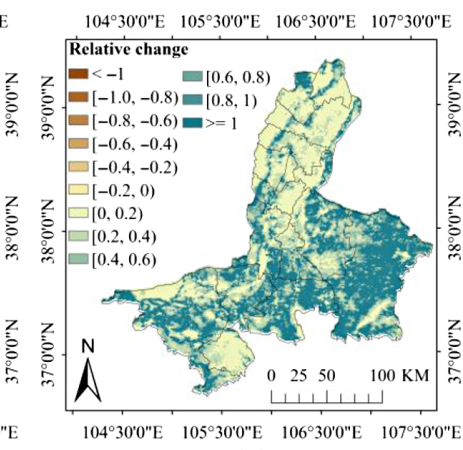

(c)

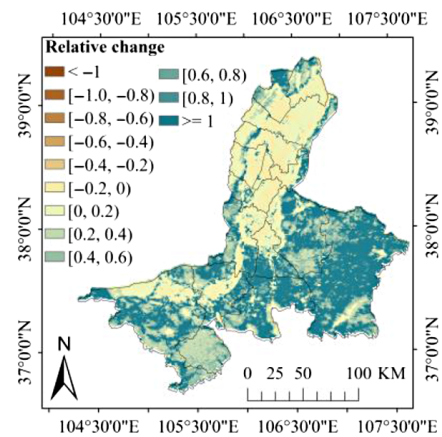

(d)

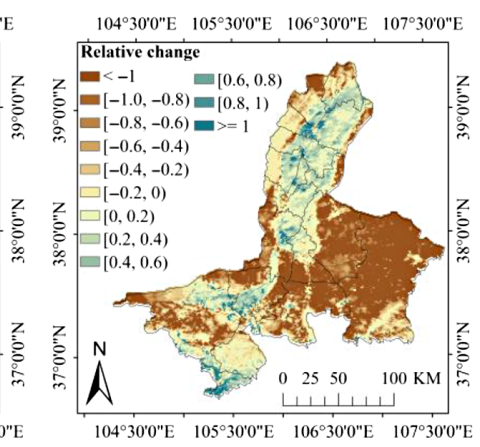

(e)

Fig. 12 Relative change of RSUAE to the perturbation of (a) EVI; (b) WET; (c) LST; (d) NDBSI; and (e) AOD through decreasing LST by $2 \mathrm{~K}$ or decreasing the other indicators by $20 \%$. 
through adding the component of air. Based on the VISA framework, we constructed a remote sensing model (RSUAE) for dynamically monitoring urban eco-environment quality. All evaluation indexes in RSUAE are derived from remote sensing data, which ensures that the urban eco-environment quality can be evaluated from a long-term and dynamic perspectives.

Second, this study explored the spatiotemporal variation of eco-environment quality in NXUA from the integration of vegetation, impervious surface, soil, and air quality. NXUA has been regarded as the heart of Ningxia's economic and social development. Monitoring and evaluating the eco-environment quality of NXUA in a dynamical and comprehensive way is very necessary for sustainable development of Ningxia. The previous evaluations mainly utilize individual index such as land cover type ${ }^{42}$ and vegetation coverage. ${ }^{40,43,44}$ We conducted a comprehensive evaluation which integrated not only the above-mentioned factors but also the indicators of air quality, land surface temperature, land surface moisture, and soil quality. We illustrated the spatiotemporal variation of eco-environment quality using Mann-Kendall trend test analysis. Moreover, we identified several hotspot areas where eco-environment quality suffers degradation during the period 2001-2019: the area at the northwest of the Shizuishan city, the area around Yinchuan city, the area around Wuzhong city, and the area around Zhongning city. Those hotspots are noteworthy for local management. We also found that the eco-environment quality in most areas of Yanchi county has improved significantly. It got the highest average value of $Z$ statistic by the Mann-Kendall test. But it is worth noting that the eco-environment of Yanchi city is more vulnerable than the other counties. Our results can provide support for local policy development.

\section{Conclusion}

This study contributes a VISA framework for monitoring the eco-environment of urban or UA area based on remote sensing. There are four basic components considered in the VISA framework: impervious surface, vegetation, soil, and air pollution. Based on the VISA framework, a RSUAE, i.e., RSUAE was proposed, which can integrate the greenness (measured by EVI), dryness and imperviousness (by NDBSI), moisture (by WET), heat (by LST), and air turbidity (by AOD). The new model was evaluated by comparing with land cover types as well as comparing with two existing models RSEI and EEQI. Evaluation results demonstrated that this new model is valid to depict the difference of eco-environment quality among varied land cover types. The RSUAE model has general consistency with the existing RSEI and EEQI models. More important, this new model takes into account well the influences of air quality which is neglected in the classical V-I-S framework and its derived remote sensing models.

The RSUAE was employed to evaluate the eco-environment quality of NXUA, China with Mann-Kendall trend test. Spatiotemporal analysis of the RSUAE indicates that $78.69 \%$ of the study area has no significant change trend, $18.73 \%$ of the whole area has a significant increasing trend, and $2.58 \%$ of the whole area suffers significant or very significant decreasing trend in ecoenvironment. The Yanchi country got the highest average value of statistic $Z$ in Mann-Kendall analysis indicating that the eco-environment quality of Yanchi has improved significantly. However, several hotspot areas with a getting worse trend in eco-environment were identified in this study. Those areas are around Yinchuan, Wuzhong, Zhongning cities, and the northwest of the Shizuishan city. Sensitivity analysis demonstrates that the southeast area is more vulnerable, which implies that the local government should pay attention to the eco-environment protection of this area. The tool and methods provide in this study could also be used for other UA areas.

\section{Acknowledgments}

This research was funded by Ningxia Key Research and Development Program, grant No. 2018BEG03069; National Natural Science Foundation of China, grant No. 41871338; and Yue Qi Young Scholar Project, CUMTB-2018. The author would like to thank NASA Land Processes Distributed Active Archive Center for providing the MODIS data. The authors declare no conflict of interest. 
Sun et al.: Evaluating eco-environment in urban agglomeration from a vegetation-impervious...

\section{References}

1. United Nations, "2018 revision of world urbanization prospects" (2018).

2. C. Fang and D. Yu, "Urban agglomeration: an evolving concept of an emerging phenomenon," Landscape Urban Plann. 162, 126-136 (2017).

3. Y. Zheng, "Spatial pattern of China's urban agglomerations: theoretical background, formation mechanisms, and latest progress of research of dispersed regional concentration," Prog. Geogr. 39, 339-352 (2020).

4. Z. Zhao, "Research on the development characteristics and route of Chinese Urban Agglomeration," Co-Oper. Econ. Sci. 1, 18-19 (2020).

5. L. H. Chai and D. Lha, "A new approach of deriving indicators and comprehensive measure for ecological environmental quality assessment," Ecol. Indic. 85, 716-728 (2018).

6. H. Q. Xu et al., "Prediction of ecological effects of potential population and impervious surface increases using a remote sensing based ecological index (RSEI)," Ecol. Indic. 93, 730-740 (2018).

7. R. S. King and M. E. Baker, "Considerations for analyzing ecological community thresholds in response to anthropogenic environmental gradients," J. N. Am. Benthol. Soc. 29(3), 998-1008 (2010).

8. S. Orfanidis, P. Panayotidis, and N. Stamatis, "An insight to the ecological evaluation index (EEI)," Ecol. Indic. 3(1), 27-33 (2003).

9. A. Li et al., "Eco-environmental vulnerability evaluation in mountainous region using remote sensing and GIS - a case study in the upper reaches of Minjiang River, China," Ecol. Modell. 192(1-2), 175-187 (2006).

10. M. A. Musse, D. A. Barona, and L. M. S. Rodriguez, "Urban environmental quality assessment using remote sensing and census data," Int. J. Appl. Earth Obs. Geoinf. 71, 95-108 (2018).

11. T. Sun et al., "Wetland ecosystem health assessment through integrating remote sensing and inventory data with an assessment model for the Hangzhou Bay, China," Sci. Total Environ. 566-567, 627-640 (2016).

12. S.-X. Wang, Y. Yao, and Y. Zhou, "Analysis of ecological quality of the environment and influencing factors in China during 2005-2010," Int. J. Environ. Res. Public Health 11(2), 1673-1693 (2014).

13. W. Wei et al., "Spatiotemporal evolution of environment based on integrated remote sensing indexes in arid inland river basin in Northwest China," Environ. Sci. Pollut. Res. 26(13), 13062-13084 (2019).

14. $\mathrm{X} . \mathrm{Hu}$ and $\mathrm{H} . \mathrm{Xu}$, "A new remote sensing index for assessing the spatial heterogeneity in urban ecological quality: a case from Fuzhou City, China," Ecol. Indic. 89, 11-21 (2018).

15. H. Q. Xu et al., "Detecting ecological changes with a remote sensing based ecological index (RSEI) produced time series and change vector analysis," Remote Sens. 11(20), 2345 (2019).

16. H. Guo et al., "Ecological environment assessment based on remote sensing in Zhengzhou," IOP Conf. Ser. Earth Environ. Sci. 94, 012190 (2017).

17. H. M. Song and L. Xue, "Dynamic monitoring and analysis of ecological environment in Weinan City, Northwest China based on RSEI model," Ying yong sheng tai xиe bao-J. Appl. Ecol. 27(12), 3913-3919 (2016).

18. H. Yue et al., "Eco-environmental quality assessment in China's 35 major cities based on remote sensing ecological index," IEEE Access 7, 51295-51311 (2019).

19. M. K. Firozjaei et al., "Remotely sensed urban surface ecological index (RSUSEI): an analytical framework for assessing the surface ecological status in urban environments," Remote Sens. 12(12), 2029 (2020).

20. M. K. Ridd, "Exploring a V-I-S (vegetation-impervious surface-soil) model for urban ecosystem analysis through remote sensing: comparative anatomy for cities," Int. J. Remote Sens. 16(12), 2165-2185 (1995).

21. R. Stirnberg, J. Cermak, and H. Andersen, "An analysis of factors influencing the relationship between satellite-derived AOD and ground-level PM10," Remote Sens. 10(9), 1353 (2018). 
Sun et al.: Evaluating eco-environment in urban agglomeration from a vegetation-impervious...

22. H. Ma and L. Shi, "Assessment of eco-environmental quality of Western Taiwan Straits Economic Zone," Environ. Monit. Assess. 188(5), 311 (2016).

23. X. Hu and $\mathrm{H}$. Xu, "A new remote sensing index based on the pressure-state-response framework to assess regional ecological change," Environ. Sci. Pollut. Res. 26(6), 5381-5393 (2019).

24. S. E. Lobser and W. B. Cohen, "MODIS tasselled cap: land cover characteristics expressed through transformed MODIS data," Int. J. Remote Sens. 28(22), 5079-5101 (2007).

25. A. Rasul, H. Balzter, and C. Smith, "Spatial variation of the daytime surface urban cool Island during the dry season in Erbil, Iraqi Kurdistan, from Landsat 8," Urban Clim. 14, 176-186 (2015).

26. A. Rasul, H. Balzter, and C. Smith, "Diurnal and seasonal variation of surface urban cool and heat islands in the semi-arid city of Erbil, Iraq," Climate 4(3), 42 (2016).

27. J. Xin et al., "Aerosol optical depth (AOD) and Ångström exponent of aerosols observed by the Chinese Sun Hazemeter Network from August 2004 to September 2005," J. Geophys. Res. 112(D5), D05203 (2007).

28. J. Wang and S. A. Christopher, "Intercomparison between satellite-derived aerosol optical thickness and PM2.5 mass: implications for air quality studies," Geophys. Res. Lett. 30(21), 2095 (2003).

29. J. A. Engel-Cox et al., "Qualitative and quantitative evaluation of MODIS satellite sensor data for regional and urban scale air quality," Atmos. Environ. 38(16), 2495-2509 (2004).

30. P. Gupta and S. A. Christopher, "Particulate matter air quality assessment using integrated surface, satellite, and meteorological products: multiple regression approach," J. Geophys. Res. Atmos. 114(D14), D14205 (2009).

31. C. Wang et al., "Ecological environment assessment based on land use simulation: a case study in the Heihe River Basin," Sci. Total Environ. 697, 133928 (2019).

32. R. Sun et al., "Effects of land-use change on eco-environmental quality in Hainan Island, China," Ecol. Indic. 109, 105777 (2020).

33. D. Machiwal et al., "Analysis of trend in temperature and rainfall time series of an Indian arid region: comparative evaluation of salient techniques," Theor. Appl. Climatol. 136(1-2), 301-320 (2019).

34. Y.-F. Sang, Z. Wang, and C. Liu, "Comparison of the MK test and EMD method for trend identification in hydrological time series," J. Hydrol. 510, 293-298 (2014).

35. M. Gocic and S. Trajkovic, "Analysis of changes in meteorological variables using MannKendall and Sen's slope estimator statistical tests in Serbia," Glob. Planet. Change 100, 172-182 (2013).

36. S. Deb and B. S. Sil, "Climate change study for the meteorological variables in the Barak River basin in North-East India," Urban Clim. 30, 100530 (2019).

37. R. Yang, "Research on regional economic disparity and coordinated development of economic zone along the Yellow River in Ningxia," Ningxia University (2017).

38. C. Xiao et al., "Spatial and temporal evolution of coordination degree between urbanization and ecological environment in Ningxia," Ningxia Eng. Technol. 18(1), 61-68 (2019).

39. R. Ma et al., "Ningxia water resource bulletin," in Ningxia Water Resource Bulletin, Ningxia Water Conservancy, Yinchuan (2005).

40. J. Wu et al., "Spatiotemporal evolution and driving force analysis of fractional vegetation coverage over the urban belt along the Yellow River in Ningxia," Arid Zone Res. 3, 696-705 (2020).

41. W. Wang et al., "Prohibited grazing policy satisfaction and life satisfaction in rural northwest China—a case study in Yanchi County, Ningxia Hui Autonomous Region," Int. J. Environ. Res. Public Health 16(22), 4374 (2019).

42. L. Du, "Study on land use/cover change in mountain areas of southern Ningxia based on RS technology," Prog. Geogr. 25(6), 94-101 (2006).

43. Z.-H. Xia et al., "Study on the change of vegetation fraction in agro-pastoral transition area based on NDVI-a case study in Yanchi County, Ningxia," Res. Soil Water Conserv. 13(6), 178-181 (2006).

44. Y. He et al., "Spatiotemporal dynamics of the vegetation in Ningxia, China using MODIS imagery," Front. Earth Sci. 14(1), 221-235 (2020). 
Sun et al.: Evaluating eco-environment in urban agglomeration from a vegetation-impervious...

Hao Sun is an associate professor at the China University of Mining and Technology-Beijing. He received his BS and MS degrees in cartography and geographic information engineering from the China University of Mining and Technology in 2008 and 2011, respectively, and his $\mathrm{PhD}$ in cartography and geographic information system from Beijing Normal University in 2014. He is the author of more than 20 journal papers and has three Chinese Invention Patents. His current research interests include remote-sensing big data, remote sensing of ecoenvironment and disaster.

Ling Wu is a graduate student with the supervisor of Hao Sun at the China University of Mining and Technology-Beijing. Ling Wu is also a staff member in Satellite Application Center for Ecology and Environment, Ministry of Ecology and Environment, China.

Jiaqi Hu is a graduate student with the supervisor of Hao Sun at the China University of Mining and Technology-Beijing.

Liru Ma is a graduate student with the supervisor of Hao Sun at the China University of Mining and Technology-Beijing.

Huan Li is a staff member of Ningxia Institute of Remote Sensing, Survey and Mapping in Ningxia, China. His job field is remote sensing technology and its application in natural resources and the environment.

Dan Wu is a staff member of Ningxia Institute of Remote Sensing, Survey and Mapping in Ningxia, China. Her job field is remote sensing technology and its application in natural resources and the environment. 